PNNL-13489

\title{
Technology Potential of Thermal Energy Storage (TES) Systems in Federal Facilities
}

W. D. Chvala, Jr.

July 2001

Prepared for the U.S. Department of Energy

Office of Energy Efficiency and Renewable Energy

Federal Energy Management Program

Under Contract DE-AC06-76RLO 1830 


\title{
DISCLAIMER
}

This report was prepared as an account of work sponsored by an agency of the United States Government. Neither the United States Government nor any agency thereof, nor Battelle Memorial Institute, nor any of their employees, makes any warranty, express or implied, or assumes any legal liability or responsibility for the accuracy, completeness, or usefulness of any information, apparatus, product, or process disclosed, or represents that its use would not infringe privately owned rights. Reference herein to any specific commercial product, process, or service by trade name, trademark, manufacturer, or otherwise does not necessarily constitute or imply its endorsement, recommendation, or favoring by the United States Government or any agency thereof, or Battelle Memorial Institute. The views and opinions of authors expressed herein do not necessarily state or reflect those of the United States Government or any agency thereof.

\author{
PACIFIC NORTHWEST NATIONAL LABORATORY \\ operated by \\ BATTELLE \\ for the \\ UNITED STATES DEPARTMENT OF ENERGY \\ under Contract DE-AC06-76RL01830
}

Ty 
PNNL-13489

\section{Technology Potential of Thermal Energy Storage (TES) Systems in Federal Facilities}

W. D. Chvala, Jr.

July 2001

Prepared for the U.S. Department of Energy

Office of Energy Efficiency and Renewable Energy

Federal Energy Management Program

Under Contract DE-AC06-76RLO 1830 


\section{Preface}

The mission of the U.S. Department of Energy's Federal Energy Management Program (FEMP) is to reduce the cost of Government by advancing energy efficiency, water conservation, and the use of solar and other renewable technologies. This is accomplished by creating partnerships, leveraging resources, transferring technology, and providing training and technical guidance and assistance to agencies. Each of these activities is directly related to achieving the requirements set forth in the Energy Policy Act of 1992 and the goals that have been established in Executive Order 13123 (June 1999), as well as supporting activities that promote sound management of Federal financial and personnel resources. The Pacific Northwest National Laboratory (PNNL) ${ }^{1}$ supports FEMP mission in all activity areas.

This document presents the findings of a technology market assessment for thermal energy storage (TES) in space cooling applications. The potential impact of TES in Federal facilities is modeled using the Federal building inventory with the appropriate climatic and energy cost data. In addition, this assessment identified acceptance issues and major obstacles through interviews with energy services companies (ESCOs), TES manufacturers, and Federal facility staff.

\footnotetext{
${ }^{1}$ The Pacific Northwest National Laboratory (PNNL) is operated for the U.S. Department of Energy by Battelle Memorial Institute under contract DE-AC06-76RLO 1830.
} 


\section{Executive Summary}

The following question \& answer session provides a quick look at thermal energy storage (TES) systems and the results of this market assessment.

Q: What is TES?

A: Thermal energy storage (a.k.a., cool storage or chilled storage) is a technology that reduces electric costs by shifting space cooling activities to off-peak times. Water is chilled or ice is made during the night to either replace or augment building cooling equipment during the day. TES can either be full storage systems, where all on-peak cooling loads are satisfied from storage, or partial storage systems (often called loadlimiting), where all the cooling load above a certain level is satisfied from storage.

Q: How much energy does TES save?

A: TES, by itself, is not an energy savings technology; it is a cost savings technology. By shifting chilling activities to off-peak times, when demand and energy rates are reduced, significant dollar savings can be realized. The economics are more compelling when TES is implemented in conjunction with an existing cooling system expansion, replacement of older cooling equipment, or new construction. In each case, energy savings will also be realized because TES allows facilities to use fewer, smaller, and/or more energy-efficient chillers.

Q: Where can TES be applied?

A: TES can be implemented anywhere cooling loads can be shifted to off-peak hours. The best applications are in office buildings, hospitals, and schools, but it will work in other buildings too. The following factors greatly influence TES suitability:

?? Electric rate structures with high demand charges, ratcheted demand charges, or large variation in hourly energy charges (peak/off-peak rates or time-of-use rates).

?? Buildings where off-peak cooling load is less than the on-peak cooling load.

?? Climates with higher temperatures during the day and cooler nights.

?? Expansion of an existing cooling system, replacement of older cooling equipment, or building expansion / new construction.

?? Available physical space to house the storage medium and associated equipment.

Q: What are the biggest obstacles to TES projects?

A: The uncertainty surrounding the future of deregulation of the electric industry is a problem because TES economics are dependent on favorable rates. Overly conservative estimates of electric rates hurt the projected payback of TES projects. Lack of experience and training on the part of facility personnel can cause opportunities to implement TES to be overlooked.

Q: What is the potential impact of TES in the Federal sector?

A: A 1994 ASHRAE study reported that between 1500-2000 TES projects were in place in the United States. Of those, less than $1 \%$ of completed TES projects were in the Federal sector. With the Federal sector representing 4 to $5 \%$ of total building floor 
area, TES is under-represented. The model developed for this study indicates that savings ranging from $\$ 28.4$ million to $\$ 42.1$ million per year could be realized through TES projects in the Federal sector. The initial costs for these projects are projected to be $\$ 176.5$ million to $\$ 183.8$ million.

Q: Can I implement TES under alternative financing?

A: Yes. TES projects have already been completed using alternative financing. Even if there is no net energy savings, significant cost savings technologies can be implemented under an energy savings performance contract (ESPC) according to OMB ESPC Guidelines (6/02/00). Federal TES projects have already been completed using direct agency funding, capital improvement funds, utility financing, and ESPCs.

Q: Should TES be promoted in the Federal sector?

A: TES should be promoted through demonstrations, success stories, and by distributing the Federal Energy Management Program (FEMP) Technology Alert. Federal facilities should, as standard practice, evaluate TES options whenever a chiller replacement is performed. Agencies should ensure that contractors are evaluating TES as an option, especially when chiller replacements are considered. 


\section{Table of Contents}

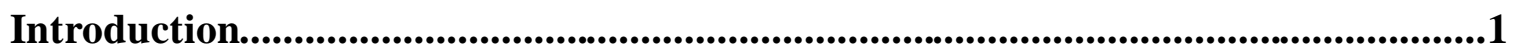

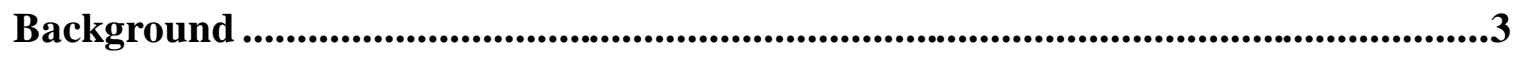

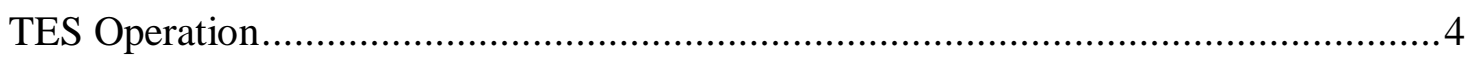

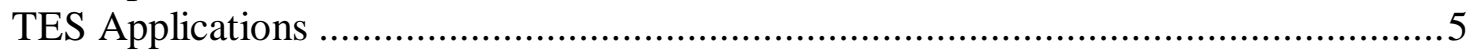

Technology Potential.......................................................................................................7

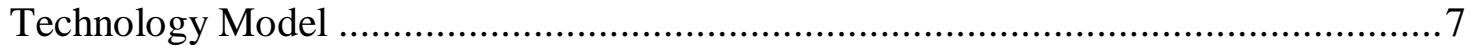

Interpreting Federal Floor Space .................................................................... 8

Cost Effectiveness ................................................................................. 10

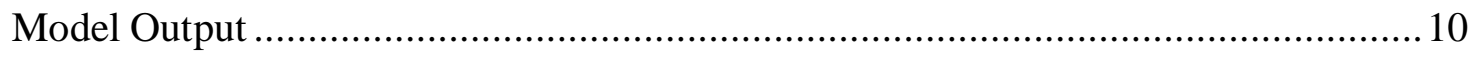

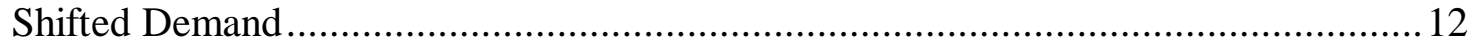

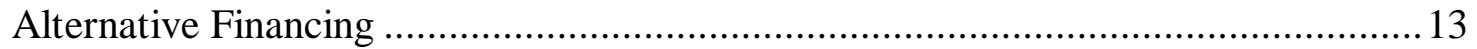

Known Limitations ............................................................................ 14

Market Potential......................................................................................15

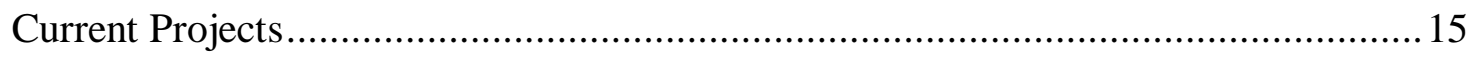

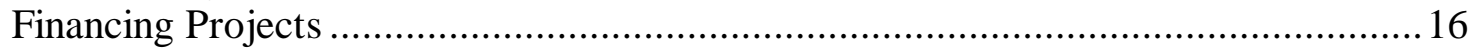

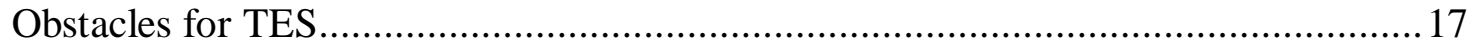

Conclusions................................................................................................................19

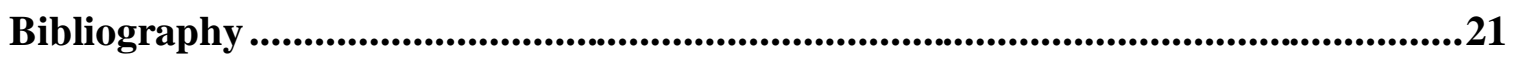

Additional Reading..........................................................................................................23

Appendix A: Electric Rate Structures ...........................................................A-1

Appendix B: Building Energy and Weather Profiles................................................B-1

Appendix C: CBECS Data............................................................................

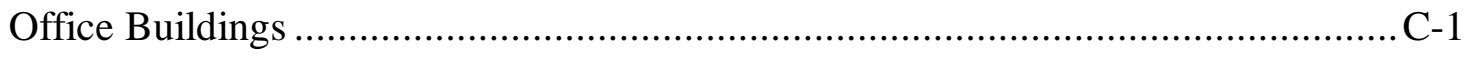




\section{Figures}

Figure 1. Operating Strategies for TES ..........................................................

Figure 2. Floor Area by Cooling Type ..........................................................

Figure 3. Potential Savings per Year from TES Projects ......................................... 11

Figure 4. Yearly Savings of Potential TES Projects ............................................. 11

Figure A1. Demand Charges Used by Model (high, mid, low) ..................................

Figure C1. Building Size Distribution by Number of Buildings .................................. 2

Figure C2. Building Floor Area by Size Bins ........................................................2

\section{Tables}

Table 1. TES Applicability to Federal Building Types ..............................................5

Table 2. Selected Model Outputs ...................................................................... 12

Table 3. Estimated Demand Shifted by TES Projects for Selected States .................... 12

Table 4. Comparing Internal Funding to Alternative Financing ................................. 13

Table A1. Electric Rate Averages by State ...........................................................

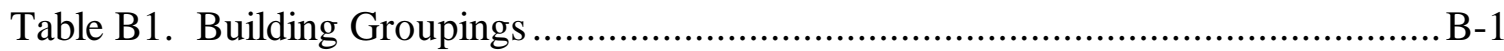




\section{Introduction}

Thermal energy storage (TES) for space cooling, also known as cool storage, is a technology that reduces electric costs by shifting chilling activities to off-peak times. Water is chilled or ice is made during off-peak hours to either replace or augment building cooling equipment during the day. Although the total energy use of the system may increase because of heat losses in storage and distribution, the reduction of peak demand and shifting of electric consumption to off-peak rates can produce substantial cost savings.

The implementation of TES - or any energy or cost savings measure - at a facility can be accomplished through a number of means. Traditionally, projects were paid for through facility budgets or direct appropriation. Later, utilities offered rebates, financing, or technical services to reduce demand on their system and postpone construction of new generating facilities. Recently, the emergence of the energy savings performance contract (ESPC) allows other parties to finance, install, and even operate projects, and receive a share of the savings generated. The ESPC financing mechanism was authorized through the Energy Policy Act of 1992 and detailed in the Final Rule on ESPC (10 CFR 436 Subpart B 4/10/1995).

This report will discuss the application of TES in two parts. First, a technical assessment of the TES technology will be performed to evaluate the technology's potential in the Federal sector. Secondly, a market assessment seeks to evaluate acceptance issues and major obstacles through interviews with energy services companies (ESCOs), TES manufacturers, and Federal facility staff. 


\section{Background}

Thermal energy storage (TES) uses the heat storage properties of a material to store heat in or alternatively cool the material for use later. The latter example - known as cool storage, chill storage, or cool thermal storage - is the more popular use of TES, driven by the high cost of electric on-peak demand and energy charges. In this process, heat is removed from a medium (you can't physically store "chill") during off-peak times and then passed through a heat exchanger to remove heat from a building in place of chiller operation. This document will deal exclusively with TES used for cool thermal storage.

TES for space cooling is a relatively mature technology that continues to improve through design advances. Cool storage technology can be used to significantly reduce energy costs by allowing energy-intensive, electrically driven cooling equipment to be predominantly operated during off-peak hours, when electricity rates are lower. Cool storage technologies come in many different forms. The storage media is most commonly water (with "cold" stored in the form of ice, chilled water, or an ice/water slurry), but other media (most notably eutectic salts) have also been used. Storage media can be cooled (charged) by evaporating refrigerant or a secondary coolant (typically a water/glycol mixture). Discharge is usually accomplished directly via circulating water or indirectly via secondary coolant.

Cool storage is not an energy savings technology per se; it is a cost savings technology. TES system efficiencies of 95 to $99 \%$ are common because of the small amount of energy lost as chilled solutions gain heat during storage and transfer. The system may use more total energy, but will experience significant energy and demand reductions during critical peak hours. The technology is a dollar savings technology by allowing facilities to reduce peak demand charges and shift electric consumption to off-peak (generally cheaper) times. TES can be viewed as an energy savings technology when it is used in conjunction with an energy-efficient chiller replacement, chiller downsizing, or in lieu of adding additional chillers. Almost all TES projects exhibit one or more of these three attributes. Whether a TES application is purely cost saving or an energy and cost saving system, it can be funded through all financing mechanisms including alternative financing according to the OMB ESPC Guidelines. (OMB, 6/02/00)

TES systems can achieve significant source energy savings depending on building airconditioning patterns, TES operating strategy and utility supply mix. In California alone, if TES achieved a $20 \%$ market penetration by 2005 , enough source energy would be saved to supply the energy needs of over one-fifth of all new air-conditioning growth during the next decade. With or without deregulation, strained electric utilities will view TES as an attractive option for the future.

Because this report is not intended to be a study of the physical processes of the technology, the reader should refer to the following documents for additional information: 
?? Thermal Energy Storage for Space Cooling. Federal Energy Management Program (FEMP), Federal Technology Alert (FTA). U.S. Department of Energy, Pacific Northwest Laboratory, Richland, Washington, December 2000.

?? James S. Elleson. Successful Cool Storage Projects: From Planning to Operation. American Society of Heating, Refrigeration and Air-Conditioning Engineers, Atlanta, Georgia, 1997.

?? Charles E. Dorgan and James S. Elleson. Design Guide for Cool Thermal Storage. American Society of Heating, Refrigeration and Air-Conditioning Engineers, Atlanta, Georgia, 1993.

\section{TES Operation}

TES systems are operated in two modes: full storage and partial storage. Full storage systems, also known as load shifting systems are designed to meet all on-peak cooling loads from storage. Partial storage systems meet part of the cooling load from storage and part directly from the chiller during the on-peak period. Figure 1 shows the building load and chiller/storage operation for each scenario. (Pacific Northwest National Laboratory, 2000)

In a full storage system, the chiller operates at its capacity during offpeak hours to charge storage and meet cooling loads during off-peak hours. During peak times, all cooling requirements are satisfied by the storage medium. This type of system results in larger and, therefore, more expensive chiller and storage units compared to partial storage systems. However, full storage also captures the greatest savings possible by shifting the most electric demand from on-peak to offpeak. Full storage systems are relatively attractive when demand charges are high, the differential between on-peak and off-peak energy charges is high and/or when the peak demand period is short.

\section{Load leveling and demand limiting} systems are both versions of partial storage. In general, partial storage systems meet part of the cooling load from storage and part directly from
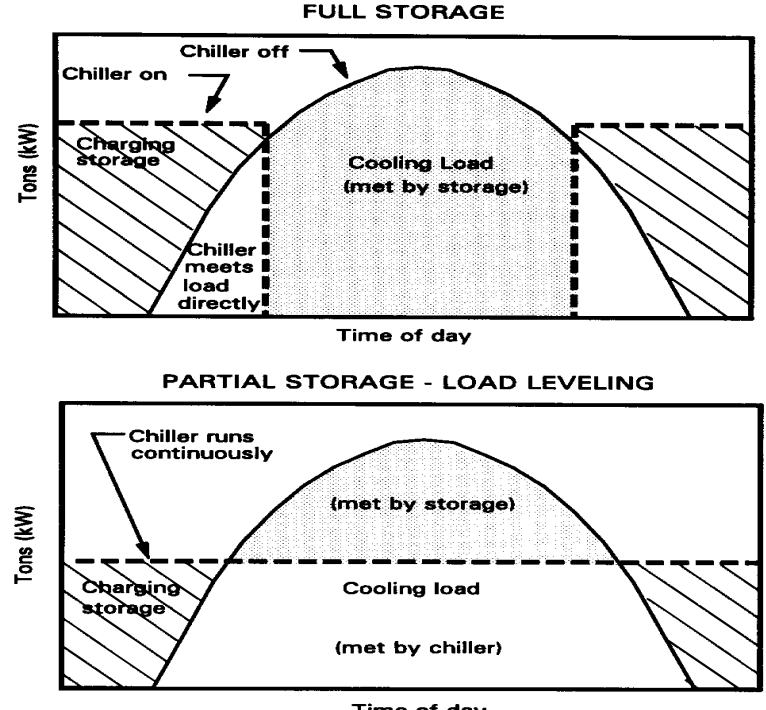

Time of day

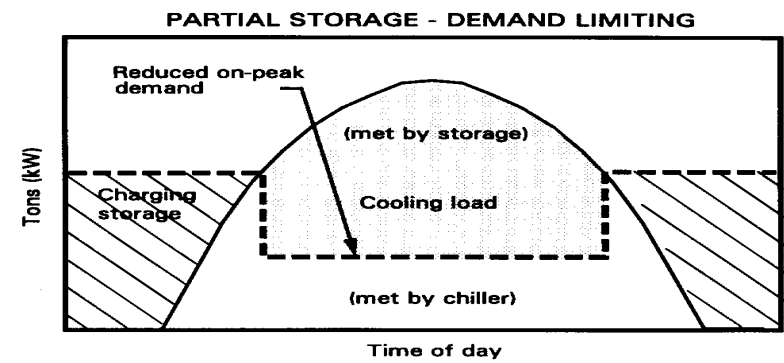

Figure 1. Operating Strategies for TES 
the chiller during the on-peak period. Load leveling versions are designed for the chiller to operate at full capacity for 24 hours a day. Storage is charged when the load is less than the output of the chiller, and discharged when the load is greater than the output of the chiller. Load leveling designs minimize the size and cost of chiller and storage components, but achieve less electricity cost savings than full storage systems. Load leveling systems are relatively attractive when electric rate incentives for load shifting are moderate, the ratio of peak to average load is high, and/or the on-peak period is long. Demand-limiting partial storage represents a middle ground between full storage and load leveling partial storage, where chiller operation is reduced but not eliminated during the on-peak period. Thus, system size and cost, and electricity cost savings tend to fall between that for the other two design options. Chiller operation in demand-limiting systems may also be controlled to minimize site peak demand, resulting in variable chiller output during the peak demand period.

TES greatly increases a facility's load factor - the ratio of consumption over peak demand - by shifting demand to off-peak hours. A higher load factor is very beneficial to the electric industry and makes the user an attractive customer.

\section{TES Applications}

Cool storage can potentially reduce the on-peak energy consumption, peak demand, and most importantly, average cost of energy consumed. While most building space cooling applications are potentially attractive candidates, the prospects will be especially attractive if one or more of the following conditions exists.

?? Electric rate structures with high demand charges, ratcheted demand charges, or large variation in hourly energy charges (peak/off-peak or time-of-use rates).

?? Buildings where off-peak cooling load is less than the peak-cooling load.

?? Climates with higher temperature gradient from day to night.

?? Expansion of an existing cooling system, replacement of older cooling equipment, or building expansion / new construction.

?? Available physical space to house the storage medium and associated equipment.

With the above criteria in mind, it can be seen (see Table 1) that certain building types in the Federal sector are attractive for TES.

Table 1. TES Applicability to Federal Building Types

\begin{tabular}{|cll|}
\hline $\begin{array}{c}\text { \% of } \\
\text { Total }\end{array}$ & Building Type & Applicability \\
\hline 5.2 & Hospital & \\
23.6 & Housing \\
4.0 & Industrial \\
4.7 & Laboratory/R\&D \\
22.2 & Office \\
2.2 & Other \\
0.6 & Prison \\
4.6 & School \\
16.2 & Services \\
16.7 & Storage \\
$\sim 0$ & Utility \\
$\bigcirc$ & Good to Excellent Potential \\
$\bigcirc$ & Average to Good Potential \\
$\bigcirc$ & Poor to Average Potential
\end{tabular}


In general, office buildings, schools, and certain laboratory / R\&D facilities are prime candidates for TES because on-peak demand can easily be shifted to unoccupied, offpeak hours. To a lesser extent, hospitals and other round-the-clock facilities may apply if there is a significant drop in off-peak loads and electric rates are favorable.

Using TES also depends on the type of cooling available in the facilities. TES is not generally applicable to buildings cooled by smaller residential or small commercial-style heat pumps, packaged air-conditioning units, or swamp coolers. The exception is when smaller "roof-top" air-conditioning units are converted to act as air-handlers for a chilled water loop served by a chiller/TES system. TES can be used in a district cooling system where multiple buildings are cooled by a chilled water loop provided by a central chiller plant. In this scenario, buildings of various sizes and use types typically not attractive to TES might also benefit from aggregating building loads.

Another important factor for TES application is the availability of space for a storage tank and associated pumps and heat exchangers. Many Federal facilities benefit from a campus-like setting, providing ample room for the storage medium. If large enough, the large chilled water storage tanks are able to take advantage of economies of scale to reduce the cost per shifted ton of refrigeration. Where space is a factor, one TES system consists of 190 ton-hr storage modules that can be joined together through a manifold. The modules can be added as needed, stacked, even stored in several rooms, indoors or out, and even buried in the ground.

The affect of the Environmental Protection Agency's ban on chlorofluorocarbons (CFCs) in chillers provides another opportunity for TES. As aging chillers are replaced, sites should consider downsizing to smaller, more efficient chillers combined with a TES system. 


\section{Technology Potential}

This portion of the assessment seeks to estimate the potential for TES in Federal facilities. For an assessment of this type, a facility-by-facility analysis for the entire Federal sector is impractical. It is impossible to know the precise rate schedules, cooling technologies, and cooling loads for every building. Instead, facilities are aggregated by state and evaluated with average values for weather data and electric rates. This analysis is meant to estimate the magnitude of the potential application for TES and not identify specific facilities where TES should be applied. Facilities should be evaluated on a caseby-case basis using site-specific attributes.

\section{Technology Model}

A model was developed to determine the potential application of TES in the Federal sector based on the building sizes and types within each facility. The model utilizes building energy-use profiles developed for the Buildings Standards Program at Pacific Northwest National Laboratory and Lawrence Berkeley National Laboratory for its analysis. The other important input variables are: site weather data and electric rate structure. Based on the inputs, the model determines if TES is applicable, what type of TES technology should be applied, and what the economics or payback for the project would be.

The following is a detailed description of the model inputs. Although the inputs were generalized for this analysis, an individual site could use the model and provide all the site-specific inputs.

?? Federal Building Data - The current Federal building inventory was obtained and separated by state. For each facility, the total floor area and total number of buildings for each building use type was provided. Building use types are: schools, services, office, research and development, storage, industrial, housing, hospital, utility, prison, and other.

?? Weather Data - Weather data for 11 U.S. cities were used for the analysis. States without a weather city used the closest available city or the one with most similar weather characteristics. For more information on the how weather data is used in the analysis, see Appendix B: Building Energy and Weather Profiles.

?? Building Cooling Loads - Cooling load profiles for 8 different building sizes in each of the 11 weather cities were utilized. The building size bins were dictated by the existing building cooling load data. For more information on the building sizes, see Appendix B: Building Energy and Weather Profiles.

?? Utility Rate Data - The utility data for each facility is the on-peak energy cost, off-peak energy cost, on-peak demand cost, number of ratchet months, and ratchet percentage. The model will also work with a time-of-use (TOU) rate, although this feature was not used in the analysis. These data are based on a previous report and adjusted slightly to account for changes in electric rates. A low, medium, and high estimate for each state were generated and fed into the model 
to account for variability in the actual electric rates an individual site may see.

For more detail on how the regional rates were developed, see the Appendix A: Electric Rate Structures.

?? Cooling Equipment Variables - The model does take into account several variables concerning the cooling equipment found in a facility. These include: chiller efficiency, a performance adjustment factor when ice storage is chosen, an air-cooled chiller cost function, a water-cooled chiller cost function, a cooling tower cost function, chilled water storage tank cost function, and an ice storage tank cost function. These variables were held constant for our nationwide comparison; however, they may be used when evaluating a specific facility. The analysis can be customized for facilities where these variables are known.

?? Utility Rebates - This field allows users to specify if any utility rebate is available for TES. It was set to zero for the analysis, but may be used when evaluating implementation options at a specific facility.

To simplify the model and deal with limitations in input data, it was decided to only model the most obvious building types: office, schools, and laboratory/R\&D. These buildings represent roughly $46 \%$ of the total Federal building inventory and the majority of TES potential (GSA Federal Floor Space data). ${ }^{2}$ By ignoring other building types that might be suitable for TES, the estimates of TES potential in the Federal sector will be conservative.

\section{Interpreting Federal Floor Space}

A complete list of Federal facilities was obtained from GSA and augmented by direct agency contact by PNNL personnel. The database lists all Federally owned facilities, the number of buildings of each use type at a facility, and the total square footage for each use type at a facility. In other words, this database does not list each individual building at a facility.

Only knowing average building size (total square footage of a building type divided by the number of buildings of that type) proved to be a limitation of these data. For example, a site with 20 office buildings with $400,000 \mathrm{ft}^{2}$ of space may have 1 building with $300,000 \mathrm{ft}^{2}$ and 19 smaller buildings, or it may have 20 buildings each with 20,000 $\mathrm{ft}^{2}$. This distinction is important for the model to determine the type of cooling and the likely TES strategy to be implemented. Without being able to run building-by-building information through the model, an alternative was sought to identify the distribution of building sizes given the total square footage and number of buildings at a site.

The solution was found in a product called Commercial Buildings Energy Consumption Survey (CBECS). CBECS is a national sample survey that collects statistical information

\footnotetext{
${ }^{2}$ By eliminating storage and service buildings from the analysis, we find that office, Laboratory/R\&D, and schools represent $46 \%$ of the building inventory based on square footage (see Figure 2). Service and storage buildings are generally large and not air-conditioned; therefore they have been removed from the analysis. Examples of buildings that fall in these categories are warehouses, vehicle garages, and aircraft service facilities.
} 
on the consumption of and expenditures for energy in U.S. commercial buildings. For more details, see Appendix C (CBECS, 1998). By querying the CBECS database for all office-type buildings and looking at the responses, a building size profile was developed describing the distribution of all sizes of office buildings. For this analysis, it was assumed that the distribution of sizes of office buildings in the Federal sector is similar to office buildings nationwide. This assumption seems reasonable considering that the building sizes and types that set Federal buildings apart from the private sector tend to be related to aircraft servicing, military housing (barracks), and other non-office building types.

In addition, the CBECS data was used to develop a profile describing what type of cooling equipment is present in office buildings (see Figure 2). We now see the two cooling equipment types that are most likely candidates for TES - chillers and district chilled water systems (ultimately a central plant with chillers) - which represent $83.6 \%$ of office building types.

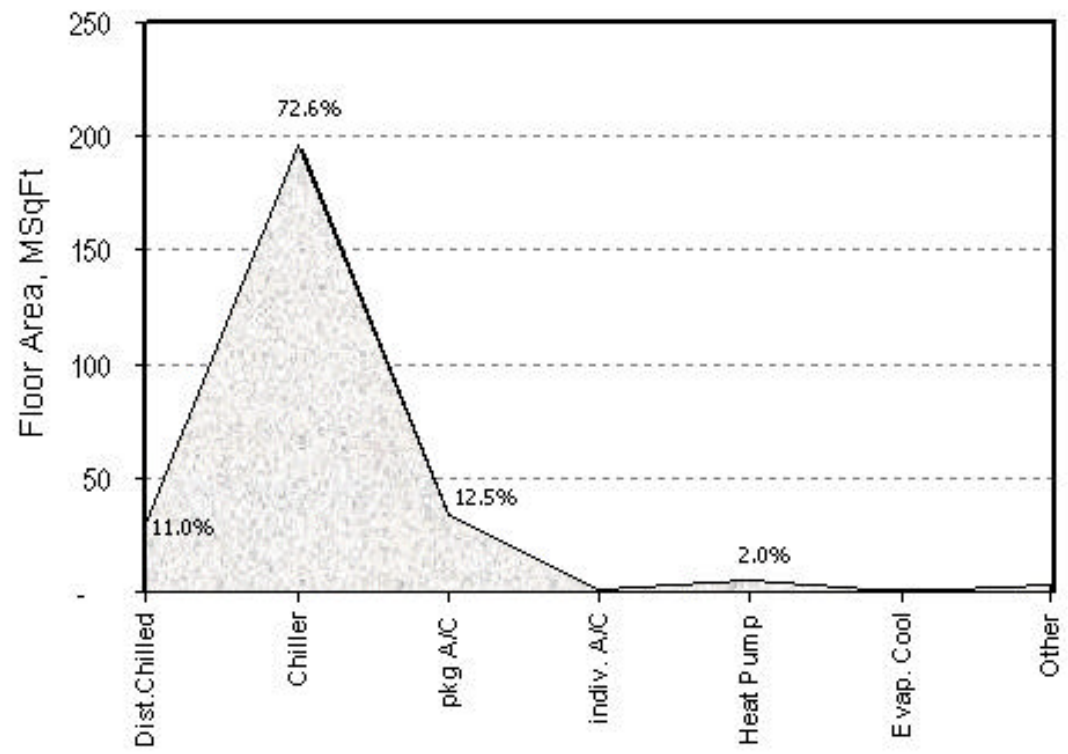

Figure 2. Floor Area by Cooling Type

The actual total floor area for Federal office buildings in each state was tabulated.

Because any size building can be served by a district chilled water loop, $11 \%$ of the floor area was placed into a single group representing buildings served by district chilled water loops.

Next, the remaining square footage was separated into eight building size bins according to the distribution of office building size distribution in the CBECS data. Because larger buildings are more likely to have chillers than smaller buildings, buildings were removed beginning with the largest size bins and placed in a group for analysis. Buildings continued to be removed for the analysis until the square footage was equal to $72.6 \%$ of the total for each state. 
Now we have two sets of buildings - those using chillers and those using a district cooling systems - in standard sizes for the model. The building data were fed into the TES model for analysis by bin, and results tabulated for each state. As a check, the Federal inventory was reconstituted from our binned and standardized buildings. Rounding errors during the binning process lost only $175,000 \mathrm{ft}^{2}$ or $0.03 \%$ of the total building inventory.

\section{Cost Effectiveness}

Which projects are cost effective? Federal facilities are required to use the Building LifeCycle Cost (BLCC) model to evaluate energy projects. The BLCC takes into account discount rates, fuel escalation rates, recurring costs, and many other parameters not expressed in the simple payback figure returned by the TES model.

The BLCC model was used to identify at what simple payback period projects would no longer be life-cycle cost effective. Using the prescribed discount rate and assumed equipment life of at least 20 years, the maximum acceptable simple payback period for a TES project in this analysis was calculated to be 13.3 years for Federal or agency financed projects. All TES projects with payback less than 13.3 years should be considered viable. In addition to the "high" value (13.3 years), medium (9.9 years) and low (6.6 years) values were identified for comparison purposes. The lower thresholds represent a greater likelihood that all projects will get implemented at those levels and will be used to evaluate the results over a range of input values.

\section{Model Output}

For a particular building, the TES model generates outputs describing the estimated cooling load parameters, the type of cooling equipment present, and the likely TES operating strategy. The model outputs that are important for the assessment are: estimated savings (\$/year), total equipment installation cost (\$), simple payback (years), and the size of storage tank required (Btus).

With so many ways to look at the outputs, probably the simplest method is to look at the projected annual savings from potential TES projects. Figure 3 shows the states with the most potential to generate savings. Remember, both electric rates and Federal floor area are strong influences, so the selected states should be no surprise.

Because of the uncertainty in some of the input values, the model was run for low, medium, and high input values for state electric rates and acceptable simple payback. By varying the inputs between our most conservative (low) to our maximum (high) values we can view the range of results from our model. Most of the results presented here will be looking at the "medium" case, with the "low" and "high" cases providing an upper or lower limit to the model output. 


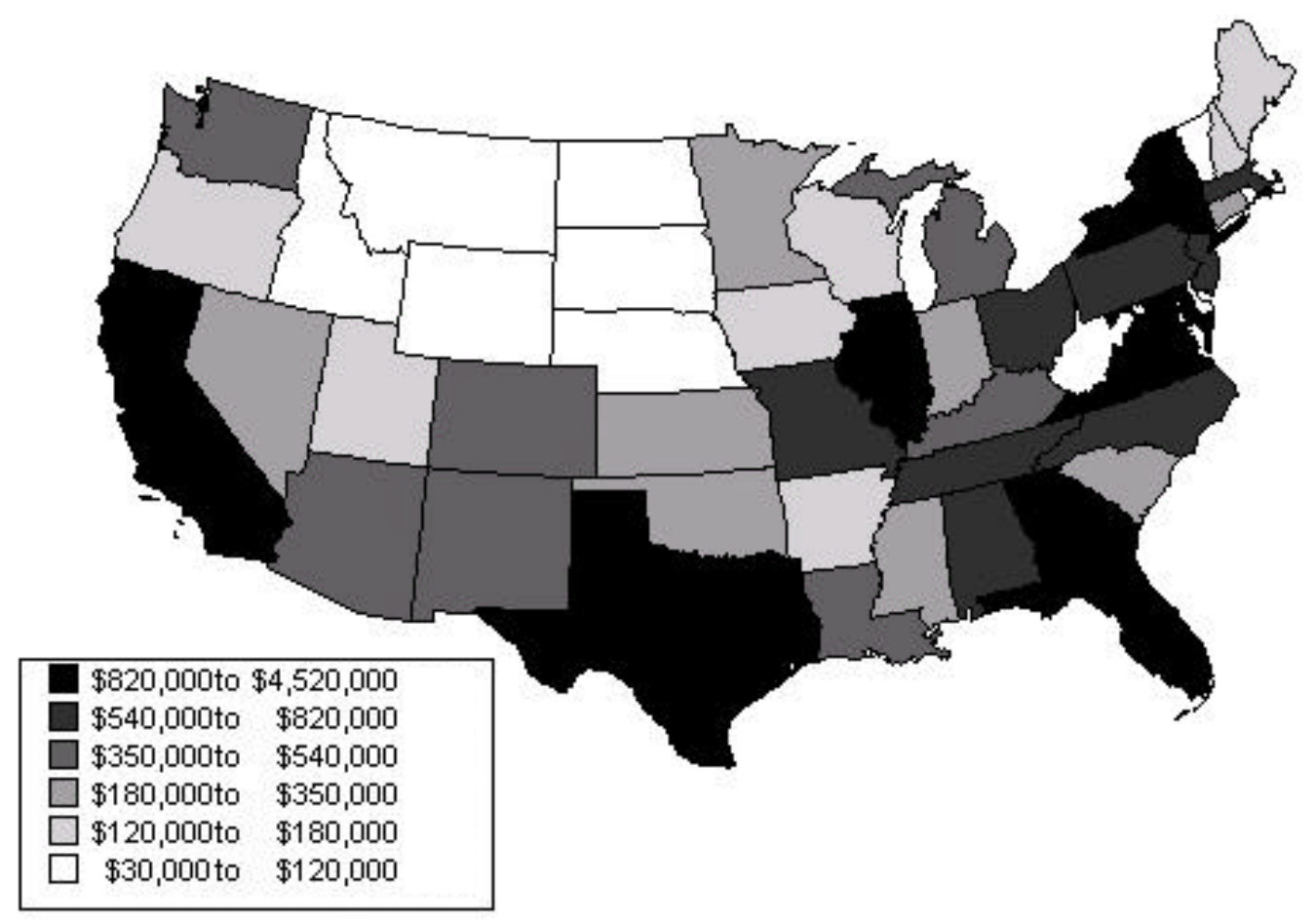

Figure 3. Potential Savings per Year from TES Projects

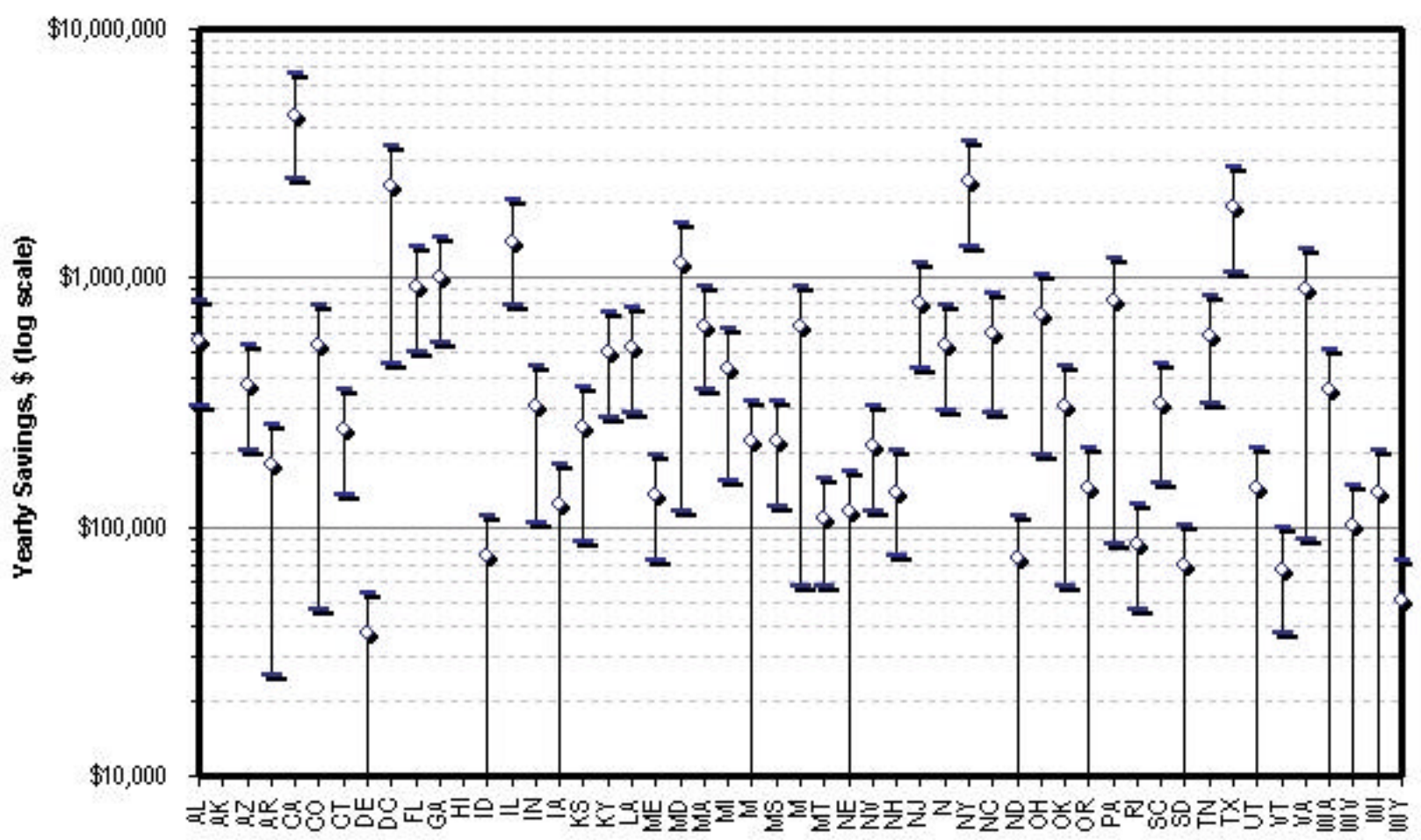

Figure 4. Yearly Savings of Potential TES Projects 
Using the "middle" simple payback maximum (9.9 years) and average electric rates, the total possible yearly savings from TES projects is projected to be $\$ 28.4$ million. The savings could reach as high as $\$ 42.1$ million per year if we look at all projects with a 13.3 year payback. Figure 4 shows the state-by-state breakdown with the error bars indicating the range between the "low" and "high" electric rates.

Other model outputs are shown in Table 2. Here one can see the range of values obtained by varying the two major inputs: simple payback and state electric rates. According to the TES model using average inputs, TES projects could impact 392 million square feet, produce an annual savings of \$28.4 million, at an implementation cost of almost \$176.5 million.

\section{Shifted Demand}

Another interesting output of the TES model is the estimated amount of electric demand shifted by TES projects. Reduced peak demand is a significant benefit in regions where generation and transmission facilities are near capacity.

According to the TES model, if all possible TES projects in the United States are implemented 3,873 MW of demand could be shifted to off-peak hours each month. Table 3 shows the projected demand shifted from TES projects in the states showing the most TES potential. (see Figures 3 and 4) While these figures indicate the potential peak demand that could be shifted, not all the peak demands are coincidental (occur at the same time).
Table 2. Selected Model Outputs

Total Cost Effective Floor Area, Square Feet

\begin{tabular}{|c|c|c|c|}
\hline & low & $\begin{array}{l}\text { Electric Rates } \\
\text { medium }\end{array}$ & high \\
\hline \multirow{3}{*}{$\begin{array}{l}\text { low } \\
\text { 兽 lodium } \\
\text { hiah }\end{array}$} & - & $212,591,500$ & $390,844,600$ \\
\hline & $90,666,700$ & $392,263,600$ & $410,462,100$ \\
\hline & $271,678,100$ & $410,462,100$ & $410,462,100$ \\
\hline
\end{tabular}

Projected Annual Savings, Dollars Per Year

\begin{tabular}{|c|c|c|c|}
\hline & low & $\begin{array}{l}\text { ectric Rates } \\
\text { medium }\end{array}$ & high \\
\hline \multirow{3}{*}{$\begin{array}{l}\text { low } \\
\frac{y}{0} \text { medium } \\
\text { high }\end{array}$} & - & $17,607,056$ & $41,095,507$ \\
\hline & $4,686,156$ & $28,375,507$ & $42,187,837$ \\
\hline & $11,725,553$ & $29,060,023$ & $42,187,837$ \\
\hline
\end{tabular}

Projected Cost for all TES Projects, Dollars

\begin{tabular}{|c|c|c|c|}
\hline & \multicolumn{3}{|c|}{ Electric Rates } \\
\hline & low & medium & high \\
\hline low & - & $93,456,180$ & $175,840,993$ \\
\hline medium & $37,986,855$ & $176,505,031$ & $183,812,419$ \\
\hline high & $120,066,884$ & $183,812,419$ & $183,812,419$ \\
\hline
\end{tabular}

Table 3. Estimated Demand Shifted by TES Projects for Selected States

\begin{tabular}{|lc|}
\hline & $\begin{array}{l}\text { Projected Demand } \\
\text { Shifted by TES } \\
\text { (MW / month) }\end{array}$ \\
\hline California & 494 \\
Washington DC & 315 \\
Texas & 299 \\
New York & 209 \\
Illinois & 192 \\
Maryland & 167 \\
Virginia & 164 \\
Georgia & 154 \\
Florida & 147 \\
Totals & $\mathbf{3 , 8 7 3}$ \\
\hline
\end{tabular}


Therefore, the actual amount of generating capacity (real power plants) displaced will be less.

\section{Alternative Financing}

Projects that are financed through special appropriations or direct agency funding accrue $100 \%$ of the energy savings from these projects. Alternative financing can bring the expertise of an ESCO to the table, along with an outside source of capital to pay for the project. In return, the facility gives up a share of the savings. Regardless of who receives the energy savings, alternatively-financed projects cost more to implement because of the added transaction costs and the cost of financing.

Because alternatively-financed projects have additional costs that internally-funded projects do not, the maximum acceptable simple payback period for a TES project in this analysis is reduced. Using the BLCC model, projects analyzed by our TES model would need a simple payback of less than 11.4 years to be life-cycle cost effective. In addition to the "high" value (11.4 years), medium (8.55 years) and low (5.7 years) values were identified for comparison purposes as before.

If we assume that all TES projects are funded through alternative financing, the market impact is reduced because projects that were on the edge of our acceptable threshold are now not considered cost effective. The results presented in Table 2 are now reduced. On average, alternatively financed TES projects could impact 363 million square feet, produce an annual savings of $\$ 26.9$ million, at an implementation cost of almost $\$ 163.3$ million. If all possible TES projects are implemented, 3,640 MW of demand could be shifted to off-peak hours.

Table 4 shows the market impact of TES, comparing the scenario where all future projects are funded internally versus all future projects funded through alternative financing. Remember, in reality, TES projects will be funded thorough a variety of sources. This figure demonstrates that the transaction costs of alternative financing make fewer projects feasible. In a perfect world, appropriations and agency funding is the best option; however, if the funds aren't there, alternative financing is a good option when compared to status quo.

Table 4. Comparing Internal Funding to Alternative Financing

\begin{tabular}{|l|cc|}
\hline & $\begin{array}{c}\text { Internally-Funded } \\
\text { Projects }\end{array}$ & $\begin{array}{c}\text { Alternatively-Financed } \\
\text { Projects }\end{array}$ \\
\hline \hline Projected Yearly Savings (\$/year) & $\$ 28.4$ million & $\$ 26.9^{1}$ \\
Total Floor Area $\left(\mathrm{ft}^{2}\right)$ & 392 million & 363 million \\
Total Project Costs $(\$)$ & $\$ 176.5$ million & $\$ 163.3$ million $^{2}$ \\
Shifted Demand (MW / month) & 3,878 & 3,640 \\
\hline
\end{tabular}

${ }^{1}$ The savings realized under alternative financing is shared between the facilities and ESCOs or utilities.

${ }^{2}$ While individual project costs may increase for alternative financing, fewer total projects are implemented. 
The results in Table 4 are for the more conservative, "average," model inputs. When we look at the "maximum" produced by using the high payback values and the high electric rate values, we see no significant difference between internally- and alternativelyfinanced projects. The high electric rates appear to produce greater savings making the same projects cost effective whether internally- and alternatively-financed.

\section{Known Limitations}

The following are known limitations to the TES model:

?? Electric Rate Averages - The values for electric rates are averages calculated based on national statistics for commercial rate structures (see Appendix A for more details). Actual sites may vary significantly from these average values. Many Federal facilities have negotiated electric rates that are below regional averages. For this reason, a type of sensitivity analysis was used in running low, average, and high electric rates to obtain a range. Sites with time-of-use (TOU) rates would likely see better performance from TES than this analysis projects.

?? Weather Data Profiles - The weather data profiles were limited to 11 cities. These cities were adequate to approximate weather profiles for all states with the exception of Alaska and Hawaii. Both states were eliminated from the analysis because of inadequate weather data.

?? Seasonal Rates - The TES model did not take into account seasonal fluctuations in rates. The majority of savings for TES will occur as a result of summer cooling loads, so it is a minor issue.

?? Leased Facilities - The Federal building inventory does not include leased facilities. The potential for application in these facilities is unknown. Conservation projects at these facilities tend to be overlooked, even though the Government ultimately pays the bill.

?? Federal Building Types - The potential application of TES will be slightly underrated because only office building types were addressed. However, this underrating is small because office buildings represent the largest potential for TES.

?? TES Projects in Place - The analysis does not take into account projects that are currently in place.

Despite these limitations, the model should produce a fair - and somewhat conservative estimate of the application potential for TES in Federal facilities. 


\section{Market Potential}

Based on the TES technology analysis conducted here, TES has the potential for significant application in the Federal sector. This portion of the assessment has a twofold purpose: first, to validate or refute the results of the technology section; and secondly, to determine interest by ESCOs, TES manufacturers, and Federal facility energy staff.

Staff members contacted utilities, TES manufacturers, Federal energy managers, and ESCOs. Each contact was asked if they are involved in any TES work, what their experience has been, and what they feel the major obstacles for TES projects are. Follow-up calls were made where appropriate.

\section{Current Projects}

An ASHRAE study estimated that 1,500 to 2,000 TES systems were installed in the U.S. as of 1994. (Potter, 1994) Federal facilities represent perhaps $1 \%$ of this total. Although not a complete list, a sample of TES projects is provided with bibliographical information where available. The U.S. Army and the Army Corps of Engineers have led the implementation of this technology in the Federal sector, followed closely by General Services Administration (GSA) and Department of Veterans

\section{Federal TES Examples:}

??VA Hospital, New Haven, CT (Braslau, 2000)

??Ralph H. J ohnson VA Medical Center, Charleston, SC

??William S. Moorhead Federal Building, Pittsburgh, PA (Klein, 1999)

??Chet Holifield Federal Center, Laguna Niguel, CA ("Chet..", 1994)

??Brookhaven National Laboratory

??Sandia National Laboratories, Albuquerque, NM

??U.S. Army Reserve Center, Monclova, $\mathrm{OH}$

??.S. Army, Fort Jackson, South Carolina. (Sohn and Cler, 1998) Affairs (VA).

The U.S. Army Corps of Engineers is currently developing or have recently completed TES projects at Fort Meade, Fort Eustis, Fort Jackson, and others. Army facilities are attractive for TES, with ample space, favorable rates, and good cooling load profiles. A recent report estimated the potential for TES in Army new construction and cooling system replacements to be $\$ 4.7$ million per year for projects having a simple payback of less than 10 years. Projects that also incorporated an equipment replacement or facility expansion experienced paybacks less than 5 years. (Sohn and Cler, 1998) Projects have been financed entirely through internal funding (capital improvement) or through the Energy Conservation Investment Program (ECIP) funding. 
The experience at Brookhaven National Laboratory is an example of what can go wrong (and right) with TES. ${ }^{3}$ During the course of the project, the electric utility cancelled their rebate program for TES, costing the project $\$ 620,000$. They survived by scaling down some design items and negotiating savings in construction costs. In addition, the economic analysis was based on Brookhaven receiving a $27 \mathrm{MW}$ block of cheap power from New York Power Authority (NYPA), with the remaining (more expensive) power coming from the local utility. During the course of the project, the block of power from NYPA was increased to $52 \mathrm{MW}$. While this is good for Brookhaven, it decreased the savings per ton of cooling shifted by TES and effectively stretched out the payback period. Even with these problems, the project has been a success. It will pay for itself, produce energy and cost savings, and even has some additional storage capacity to handle load growth at the site.

\section{Financing Projects}

TES projects can be financed though a variety of sources. Internally, direct appropriations, agency capital improvement funds, and energy conservation or special project funds (e.g., Energy Conservation Investment Program, ECIP) are funding sources that don't add an additional cost to secure financing. External funding sources in the form of utility or ESCO financing, add additional costs but can also contribute technical expertise and project management skills to a project.

It is always a good idea to work with the local electric utility. Most utilities appreciate that TES benefits them by reducing peak-demand and may provide technical support, design assistance, and occasionally financial incentives. The recent power crisis in California (January 2001) highlights the need for technologies like TES that reduce peak demand (in this case by shifting demand to off-peak hours). Utilities in states like Florida and California are once again providing financial rebates that help pay a portion of project costs based on the amount of peak demand shifted.

Obtaining alternative financing for a TES project is no different than any other capital intensive ESPC project, such as a chiller replacement. The up-front costs for a chiller/TES project will be greater than the chiller alone. The return on investment, however, may be better for the chiller/TES project because of the additional savings generated by TES. On any project, higher up-front costs (construction and equipment purchases) will reduce the net present value of the project and lengthen the period of cost recovery.

\footnotetext{
${ }^{3}$ Based on discussions with Mark Toscano, Brookhaven National Laboratory Energy Manager, and an internal white paper titled "Integration of a Chilled Water Storage System to a Central Chilled Water Facility", September, 1998.
} 


\section{Obstacles for TES}

The greatest obstacle to TES, according to the ESCOs and Federal facility staff interviewed for this assessment, is the uncertainty surrounding electric utilities and deregulation of the industry. With a technology so dependent on a specific type of rate schedule for economic viability, uncertainty about the path of future rates represents an extra degree of risk. This risk is managed by overly conservative (low) rate estimates in project planning, which in turn increases the projected payback for the technology. Historically, rates have been much lower off-peak and in the competitive environment caused by deregulation this should only increase the difference. Eventually, changes in the electric industry such as real-time pricing will favor load-reducing technologies such as TES.

Lack of expertise can be another problem for TES. Facility staff generally have the necessary experience to specify, procure, and install a chiller replacement for a facility, but are likely to be unfamiliar with TES. Without knowing, an important opportunity may have been missed to install a smaller chiller and a TES system. Federal agencies should take steps to ensure that when chiller replacements are proposed under alternative financing, TES is also evaluated as an option. This should be the case for both retrofits and new construction, which some industry professionals feel is an often over-looked arena for TES and many other energy savings technologies.

TES equipment does require some additional maintenance of pumps, heat exchangers, and control equipment, which should be identified during project planning. In addition, proper operation of the TES system is very important to achieving the savings. The daily charge and discharge of thermal energy in the storage media can be controlled from the HVAC energy management and control system. However, operators must ensure that normal maintenance activities do not interfere with the charging of the TES system. One poorly planned outage on a summer night could mean not enough capacity will be present to meet the peak cooling load during the day. With the demand charge ratchets in most electric rates, a high demand peak will affect the demand charges (and thus the cost savings) for months to come. However, most operators use the storage as an advantage during maintenance, using it to cover for down chillers and other unexpected interruptions. Any facility implementing a TES project must make sure its staff receive the appropriate training from the ESCO or contractor and that its staff are committed to operating the TES system affectively. 


\section{Conclusions}

Thermal energy storage is a viable technology for many facilities in the Federal sector. It has already been implemented in Federal buildings utilizing a range of financing - capital improvement funds, utility financing, agency funding, and performance contracting. It is a technology that has fair economics on its own and good economics when coupled with a chiller replacement, system expansion, or new construction.

TES is highly dependent on favorable electric rates. Should those rates change midproject, the projected savings could be jeopardized. With the uncertainly surrounding deregulation in the electric industry, future dollar estimates are very conservative. With or without deregulation, strained electric utilities will view TES as an attractive option for the future. As the electric industry stabilizes, and real-time or time-of-use pricing becomes more common, TES will become a more attractive technology.

Lack of expertise can be a problem for TES. Facility staff generally have the necessary experience to specify, procure, and install a chiller replacement for a facility. However, their lack of knowledge of TES could mean that an important opportunity to install a smaller chiller and a TES system may be missed. Federal facilities should, as standard practice, evaluate TES options whenever a chiller retrofit or replacement is performed. Federal agencies should take steps to ensure that ESCOs and/or utilities providing energy services are considering TES for any project that involves a chiller replacement.

TES could be utilized at many more Federal sites and should be promoted as a significant cost and energy savings technology. 


\section{Bibliography}

Braslau, D. Customer Case Study: VA Connecticut Healthcare System. Company Brochure, EUA Cogenex Corporation, Lowell, Massachusetts.

Brown, D.R., S.M. Garrett, and J.M. Sedgewick. 1991. Electric Rate Structures for Thermal Energy Storage Evaluation. PNL-7697 Pacific Northwest Laboratory, Richland, Washington.

"Chet Holifield Federal Office Building" Federal Energy Management Program: Greening Federal Facilities, 1994. http://www.eren.doe.gov/femp/greenfed/success/b6_chet_holifield.htm

Commercial Buildings Energy Consumption Survey (CBECS). National Energy Information Center, Energy Information Administration, Washington, D.C. 1998.

Dorgan, C.E. and J.S. Elleson. 1993. Design Guide for Cool Thermal Storage. American Society of Heating, Refrigeration and Air-Conditioning Engineers, Atlanta, Georgia.

Elleson, J.S. 1997. Successful Cool Storage Projects: From Planning to Operation. American Society of Heating, Refrigeration and Air-Conditioning Engineers, Atlanta, Georgia.

Klein, J. July 1999. "Thermal Storage Retrofit Reduces Costs for Federal Building." Energy User News, pp 24-25.

Office of Management and Budget (OMB) "Energy Savings Performance Contracting At Department Of Energy Sites: ESPC_Guidelines On Recurring Legal Issues." OMB Ruling, June 2, 2000.

Pacific Northwest Laboratory. December 2000. Thermal Energy Storage for Space Cooling. Federal Energy Management Program (FEMP), Federal Technology Alert (FTA). Richland, Washington.

Potter, R.A. 1994. Study of the Operational Experience with Thermal Storage Systems. ASHRAE Research Project 766. American Society of Air Conditioning Engineers. Atlanta, Georgia.

Sohn, C.W. and G.L. Cler. Assessment of Market Potential in Storage Cooling Systems for Army Facilities. ASHRAE Transactions, AT90-13-2, pp 1080-1086. 


\section{Additional Reading}

Bahnfleth, W.P. and W.S. Joyce. 1995. "Stratified Storage Economically Increases Capacity and Efficiency of Campus Chilled Water System." ASHRAE Journal. 37(4):46-49.

Caldwell, J.S. and W.P. Bahnfleth. September 1997. "Chilled Water Thermal Energy Storage without Electric Rate Incentives or Rebates." Journal of Architectural Engineering, pp 133-140.

California Energy Commission (CEC). Source Energy and Environmental Impacts of Thermal Energy Storage. February 1996.

Song, C.W, J. Fuchs, and M. Gruber. November 1998. Chilled Water Storage System at Fort Jackson, SC. U.S. Army Corps of Engineers, Construction Research Laboratories. Technical Report 99/006. 


\section{Appendix A: Electric Rate Structures}

Published electric rates for utilities in the United States are available from a variety of sources. However, for an analysis of this type, detailed rates are needed, not just a blended rate. For example, the total utility revenue divided by the energy produced (in kilowatt-hours) produces a "blended" electric rate in dollars per kilowatt-hour $(\$ / \mathrm{kWh})$. This rate "blends" together all the specific charges. Electric rates have many variables to consider, including on- and off-peak rates, seasonal rates, demand ratchets, power factor charges, and other charges. In addition, each utility will likely have several (if not many) commercial or industrial rates that are charged to government facilities. From the information available, it was impossible to match each Federal facility to a specific service provider and know exactly what rate they fall under.

Using an average blended electric rates either by utility or by state does not help the TES analysis. The cost savings from TES is dependent on a reduced off-peak demand and consumption rate. Additional savings are realized when peak demand is reduced, especially if there is a demand ratchet in effect. To get the level of detail required, the researchers revisited a report written in 1991, which had looked in detail at electric rates and developed some average energy and consumption rates (Brown, 1991). To account for variations among utilities and between commercial and industrial rates within a utility, a high and low rate were also developed for each state. The availability of low, average, and high rates allows a sensitivity analysis of sorts to determine best and worstcase scenarios. Because the report is 10 years old, the blended rate was looked at against currently available blended rates, and the figures adjusted accordingly.

Although mergers and deregulation have had a tremendous effect on electric rates throughout the United States, this method was the best available that would capture more than just a simple blended rate and allow a sensitivity analysis. The inaccuracies are acceptable for this aggregate analysis. If the model is used for evaluation of a specific facility, the actual rates should be substituted.

The actual electric rates used in this analysis are shown in Figure A1. This figure shows the range of the sensitivity analysis in the error bars on the plot. The exact values are provided in Table A1. 


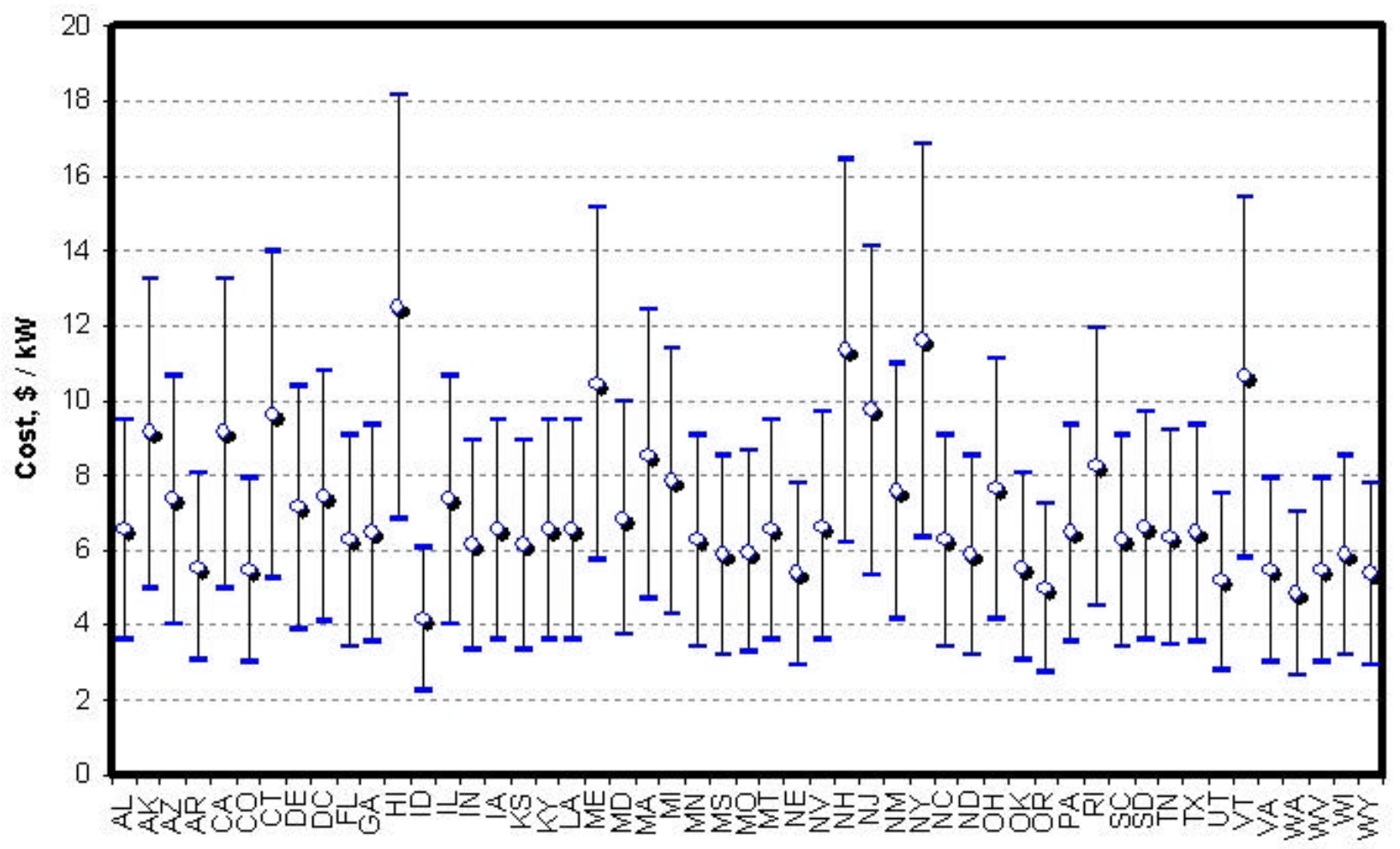

Figure A1. Demand Charges Used by Model (high, mid, low)

\section{How to read the Chart:}

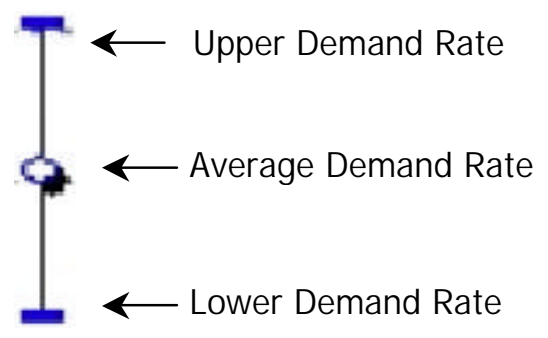

Actual demand rate will fall somewhere in this range. 
Table A1. Electric Rate Averages by State

\begin{tabular}{|c|c|c|c|c|c|c|c|c|c|c|c|c|c|c|}
\hline \multirow[b]{2}{*}{ 志 } & \multirow[b]{2}{*}{ 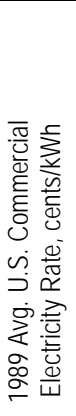 } & \multirow[b]{2}{*}{ 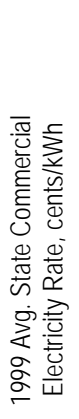 } & \multicolumn{2}{|c|}{$\begin{array}{l}\text { Flat Demand and } \\
\text { Energy Charge }\end{array}$} & \multicolumn{2}{|c|}{$\begin{array}{l}\text { Flat Demand and } \\
\text { Energy Charge }\end{array}$} & \multicolumn{2}{|c|}{$\begin{array}{l}\text { Flat Demand and } \\
\text { Energy Charge }\end{array}$} & \multicolumn{2}{|c|}{$\begin{array}{l}\text { Flat Demand and } \\
\text { Energy Charge }\end{array}$} & \multicolumn{2}{|c|}{$\begin{array}{l}\text { Flat Demand and } \\
\text { Energy Charge }\end{array}$} & \multicolumn{2}{|c|}{$\begin{array}{c}\text { Flat Demand and } \\
\text { Energy Charge }\end{array}$} \\
\hline & & & 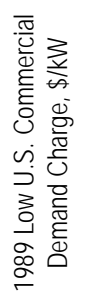 & 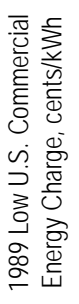 & 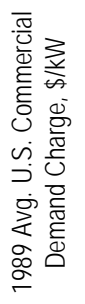 & 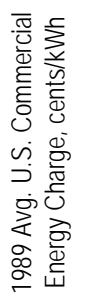 & 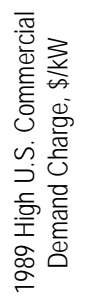 & 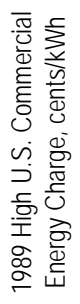 & 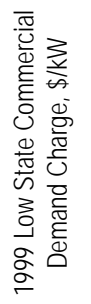 & 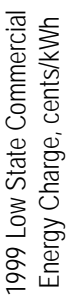 & 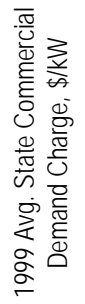 & 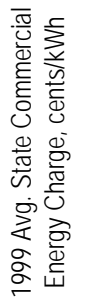 & 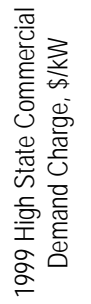 & 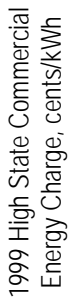 \\
\hline $\mathrm{AL}$ & 7.2 & 6.6 & 3.92 & 4.17 & 7.15 & 4.17 & 10.38 & 4.17 & 3.59 & 3.82 & 6.55 & 3.82 & 9.52 & 3.82 \\
\hline AK & 7.2 & 9.2 & 3.92 & 4.17 & 7.15 & 4.17 & 10.38 & 4.17 & 5.01 & 5.33 & 9.14 & 5.33 & 13.26 & 5.33 \\
\hline$A Z$ & 7.2 & 7.4 & 3.92 & 4.17 & 7.15 & 4.17 & 10.38 & 4.17 & 4.03 & 4.29 & 7.35 & 4.29 & 10.67 & 4.29 \\
\hline AR & 7.2 & 5.6 & 3.92 & 4.17 & 7.15 & 4.17 & 10.38 & 4.17 & 3.05 & 3.24 & 5.56 & 3.24 & 8.07 & 3.24 \\
\hline CA & 7.2 & 9.2 & 3.92 & 4.17 & 7.15 & 4.17 & 10.38 & 4.17 & 5.01 & 5.33 & 9.14 & 5.33 & 13.26 & 5.33 \\
\hline $\mathrm{CO}$ & 7.2 & 5.5 & 3.92 & 4.17 & 7.15 & 4.17 & 10.38 & 4.17 & 2.99 & 3.19 & 5.46 & 3.19 & 7.93 & 3.19 \\
\hline CT & 7.2 & 9.7 & 3.92 & 4.17 & 7.15 & 4.17 & 10.38 & 4.17 & 5.28 & 5.62 & 9.63 & 5.62 & 13.98 & 5.62 \\
\hline $\mathrm{DE}$ & 7.2 & 7.2 & 3.92 & 4.17 & 7.15 & 4.17 & 10.38 & 4.17 & 3.92 & 4.17 & 7.15 & 4.17 & 10.38 & 4.17 \\
\hline DC & 7.2 & 7.5 & 3.92 & 4.17 & 7.15 & 4.17 & 10.38 & 4.17 & 4.08 & 4.34 & 7.45 & 4.34 & 10.81 & 4.34 \\
\hline $\mathrm{FL}$ & 7.2 & 6.3 & 3.92 & 4.17 & 7.15 & 4.17 & 10.38 & 4.17 & 3.43 & 3.65 & 6.26 & 3.65 & 9.08 & 3.65 \\
\hline GA & 7.2 & 6.5 & 3.92 & 4.17 & 7.15 & 4.17 & 10.38 & 4.17 & 3.54 & 3.76 & 6.45 & 3.76 & 9.37 & 3.76 \\
\hline $\mathrm{HI}$ & 7.2 & 12.6 & 3.92 & 4.17 & 7.15 & 4.17 & 10.38 & 4.17 & 6.86 & 7.30 & 12.51 & 7.30 & 18.17 & 7.30 \\
\hline ID & 7.2 & 4.2 & 3.92 & 4.17 & 7.15 & 4.17 & 10.38 & 4.17 & 2.29 & 2.43 & 4.17 & 2.43 & 6.06 & 2.43 \\
\hline IL & 7.2 & 7.4 & 3.92 & 4.17 & 7.15 & 4.17 & 10.38 & 4.17 & 4.03 & 4.29 & 7.35 & 4.29 & 10.67 & 4.29 \\
\hline IN & 7.2 & 6.2 & 3.92 & 4.17 & 7.15 & 4.17 & 10.38 & 4.17 & 3.38 & 3.59 & 6.16 & 3.59 & 8.94 & 3.59 \\
\hline $\mathrm{IA}$ & 7.2 & 6.6 & 3.92 & 4.17 & 7.15 & 4.17 & 10.38 & 4.17 & 3.59 & 3.82 & 6.55 & 3.82 & 9.52 & 3.82 \\
\hline KS & 7.2 & 6.2 & 3.92 & 4.17 & 7.15 & 4.17 & 10.38 & 4.17 & 3.38 & 3.59 & 6.16 & 3.59 & 8.94 & 3.59 \\
\hline KY & 7.2 & 6.6 & 3.92 & 4.17 & 7.15 & 4.17 & 10.38 & 4.17 & 3.59 & 3.82 & 6.55 & 3.82 & 9.52 & 3.82 \\
\hline LA & 7.2 & 6.6 & 3.92 & 4.17 & 7.15 & 4.17 & 10.38 & 4.17 & 3.59 & 3.82 & 6.55 & 3.82 & 9.52 & 3.82 \\
\hline ME & 7.2 & 10.5 & 3.92 & 4.17 & 7.15 & 4.17 & 10.38 & 4.17 & 5.72 & 6.08 & 10.43 & 6.08 & 15.14 & 6.08 \\
\hline MD & 7.2 & 6.9 & 3.92 & 4.17 & 7.15 & 4.17 & 10.38 & 4.17 & 3.76 & 4.00 & 6.85 & 4.00 & 9.95 & 4.00 \\
\hline MA & 7.2 & 8.6 & 3.92 & 4.17 & 7.15 & 4.17 & 10.38 & 4.17 & 4.68 & 4.98 & 8.54 & 4.98 & 12.40 & 4.98 \\
\hline MI & 7.2 & 7.9 & 3.92 & 4.17 & 7.15 & 4.17 & 10.38 & 4.17 & 4.30 & 4.58 & 7.85 & 4.58 & 11.39 & 4.58 \\
\hline MN & 7.2 & 6.3 & 3.92 & 4.17 & 7.15 & 4.17 & 10.38 & 4.17 & 3.43 & 3.65 & 6.26 & 3.65 & 9.08 & 3.65 \\
\hline MS & 7.2 & 5.9 & 3.92 & 4.17 & 7.15 & 4.17 & 10.38 & 4.17 & 3.21 & 3.42 & 5.86 & 3.42 & 8.51 & 3.42 \\
\hline MO & 7.2 & 6.0 & 3.92 & 4.17 & 7.15 & 4.17 & 10.38 & 4.17 & 3.27 & 3.48 & 5.96 & 3.48 & 8.65 & 3.48 \\
\hline MT & 7.2 & 6.6 & 3.92 & 4.17 & 7.15 & 4.17 & 10.38 & 4.17 & 3.59 & 3.82 & 6.55 & 3.82 & 9.52 & 3.82 \\
\hline $\mathrm{NE}$ & 7.2 & 5.4 & 3.92 & 4.17 & 7.15 & 4.17 & 10.38 & 4.17 & 2.94 & 3.13 & 5.36 & 3.13 & 7.79 & 3.13 \\
\hline NV & 7.2 & 6.7 & 3.92 & 4.17 & 7.15 & 4.17 & 10.38 & 4.17 & 3.65 & 3.88 & 6.65 & 3.88 & 9.66 & 3.88 \\
\hline $\mathrm{NH}$ & 7.2 & 11.4 & 3.92 & 4.17 & 7.15 & 4.17 & 10.38 & 4.17 & 6.21 & 6.60 & 11.32 & 6.60 & 16.44 & 6.60 \\
\hline $\mathrm{NJ}$ & 7.2 & 9.8 & 3.92 & 4.17 & 7.15 & 4.17 & 10.38 & 4.17 & 5.34 & 5.68 & 9.73 & 5.68 & 14.13 & 5.68 \\
\hline NM & 7.2 & 7.6 & 3.92 & 4.17 & 7.15 & 4.17 & 10.38 & 4.17 & 4.14 & 4.40 & 7.55 & 4.40 & 10.96 & 4.40 \\
\hline NY & 7.2 & 11.7 & 3.92 & 4.17 & 7.15 & 4.17 & 10.38 & 4.17 & 6.37 & 6.78 & 11.62 & 6.78 & 16.87 & 6.78 \\
\hline NC & 7.2 & 6.3 & 3.92 & 4.17 & 7.15 & 4.17 & 10.38 & 4.17 & 3.43 & 3.65 & 6.26 & 3.65 & 9.08 & 3.65 \\
\hline ND & 7.2 & 5.9 & 3.92 & 4.17 & 7.15 & 4.17 & 10.38 & 4.17 & 3.21 & 3.42 & 5.86 & 3.42 & 8.51 & 3.42 \\
\hline
\end{tabular}




\begin{tabular}{|c|c|c|c|c|c|c|c|c|c|c|c|c|c|c|}
\hline \multirow[b]{2}{*}{ 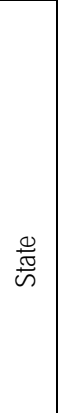 } & \multirow[b]{2}{*}{ 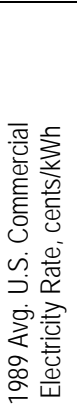 } & \multirow[b]{2}{*}{ 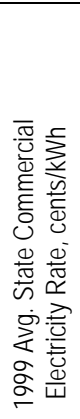 } & \multicolumn{2}{|c|}{$\begin{array}{l}\text { Flat Demand and } \\
\text { Energy Charge }\end{array}$} & \multicolumn{2}{|c|}{$\begin{array}{l}\text { Flat Demand and } \\
\text { Energy Charge }\end{array}$} & \multicolumn{2}{|c|}{$\begin{array}{l}\text { Flat Demand and } \\
\text { Energy Charge }\end{array}$} & \multicolumn{2}{|c|}{$\begin{array}{l}\text { Flat Demand and } \\
\text { Energy Charge }\end{array}$} & \multicolumn{2}{|c|}{$\begin{array}{l}\text { Flat Demand and } \\
\text { Energy Charge }\end{array}$} & \multicolumn{2}{|c|}{$\begin{array}{l}\text { Flat Demand and } \\
\text { Energy Charge }\end{array}$} \\
\hline & & & 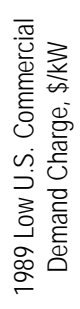 & 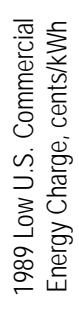 & 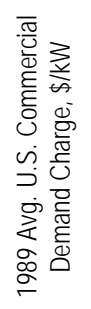 & 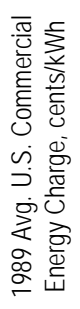 & 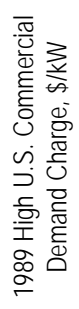 & 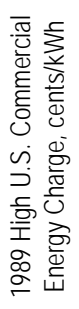 & 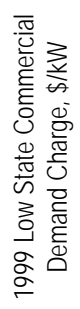 & 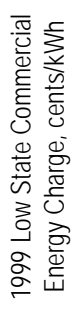 & 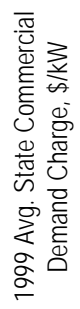 & 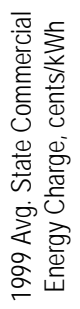 & 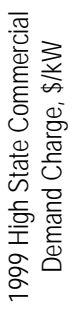 & 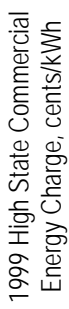 \\
\hline $\mathrm{OH}$ & 7.2 & 7.7 & 3.92 & 4.17 & 7.15 & 4.17 & 10.38 & 4.17 & 4.19 & 4.46 & 7.65 & 4.46 & 11.10 & 4.46 \\
\hline OK & 7.2 & 5.6 & 3.92 & 4.17 & 7.15 & 4.17 & 10.38 & 4.17 & 3.05 & 3.24 & 5.56 & 3.24 & 8.07 & 3.24 \\
\hline OR & 7.2 & 5.0 & 3.92 & 4.17 & 7.15 & 4.17 & 10.38 & 4.17 & 2.72 & 2.90 & 4.97 & 2.90 & 7.21 & 2.90 \\
\hline PA & 7.2 & 6.5 & 3.92 & 4.17 & 7.15 & 4.17 & 10.38 & 4.17 & 3.54 & 3.76 & 6.45 & 3.76 & 9.37 & 3.76 \\
\hline $\mathrm{RI}$ & 7.2 & 8.3 & 3.92 & 4.17 & 7.15 & 4.17 & 10.38 & 4.17 & 4.52 & 4.81 & 8.24 & 4.81 & 11.97 & 4.81 \\
\hline SC & 7.2 & 6.3 & 3.92 & 4.17 & 7.15 & 4.17 & 10.38 & 4.17 & 3.43 & 3.65 & 6.26 & 3.65 & 9.08 & 3.65 \\
\hline SD & 7.2 & 6.7 & 3.92 & 4.17 & 7.15 & 4.17 & 10.38 & 4.17 & 3.65 & 3.88 & 6.65 & 3.88 & 9.66 & 3.88 \\
\hline TN & 7.2 & 6.4 & 3.92 & 4.17 & 7.15 & 4.17 & 10.38 & 4.17 & 3.48 & 3.71 & 6.36 & 3.71 & 9.23 & 3.71 \\
\hline TX & 7.2 & 6.5 & 3.92 & 4.17 & 7.15 & 4.17 & 10.38 & 4.17 & 3.54 & 3.76 & 6.45 & 3.76 & 9.37 & 3.76 \\
\hline UT & 7.2 & 5.2 & 3.92 & 4.17 & 7.15 & 4.17 & 10.38 & 4.17 & 2.83 & 3.01 & 5.16 & 3.01 & 7.50 & 3.01 \\
\hline VT & 7.2 & 10.7 & 3.92 & 4.17 & 7.15 & 4.17 & 10.38 & 4.17 & 5.83 & 6.20 & 10.63 & 6.20 & 15.43 & 6.20 \\
\hline VA & 7.2 & 5.5 & 3.92 & 4.17 & 7.15 & 4.17 & 10.38 & 4.17 & 2.99 & 3.19 & 5.46 & 3.19 & 7.93 & 3.19 \\
\hline WA & 7.2 & 4.9 & 3.92 & 4.17 & 7.15 & 4.17 & 10.38 & 4.17 & 2.67 & 2.84 & 4.87 & 2.84 & 7.06 & 2.84 \\
\hline WV & 7.2 & 5.5 & 3.92 & 4.17 & 7.15 & 4.17 & 10.38 & 4.17 & 2.99 & 3.19 & 5.46 & 3.19 & 7.93 & 3.19 \\
\hline WI & 7.2 & 5.9 & 3.92 & 4.17 & 7.15 & 4.17 & 10.38 & 4.17 & 3.21 & 3.42 & 5.86 & 3.42 & 8.51 & 3.42 \\
\hline WY & 7.2 & 5.4 & 3.92 & 4.17 & 7.15 & 4.17 & 10.38 & 4.17 & 2.94 & 3.13 & 5.36 & 3.13 & 7.79 & 3.13 \\
\hline
\end{tabular}




\section{Appendix B: Building Energy and Weather Profiles}

The TES model utilizes building energy-use and weather profiles developed for the Buildings Standards Program at Pacific Northwest National Laboratory and Lawrence Berkeley National Laboratory for its analysis.

The building size bins used in the TES model were developed in previous work for the Building Standards Program. All buildings are fit into one of the eight categories shown below based on their floor area. A number of parameters were developed to describe a "typical" building in one of these size bins. These include the number of cooling zones per floor, the number of floors in the building, the aspect ratio of the building footprint, the average floor area, and cooling load profiles for each of the weather zones. Some of these are shown in Table B1. All buildings in the TES analysis were placed into one of these size bins to relate it to a cooling load profile for the analysis.

Table B1. Building Groupings

\begin{tabular}{|lllll|}
\hline bldg.type & n.zones.floor & n.floors & aspect.ratio & area \\
\hline \hline 1 & 5 & 3 & 1.99 & 3,000 \\
2 & 5 & 3 & 2.307 & 7,000 \\
3 & 5 & 4 & 2.407 & 17,500 \\
4 & 5 & 4 & 2.925 & 35,000 \\
5 & 5 & 7 & 1.741 & 80,000 \\
6 & 5 & 8 & 2.762 & 140,000 \\
7 & 5 & 20 & 3.22 & 350,000 \\
8 & 5 & 20 & 1.932 & 600,000 \\
\hline
\end{tabular}

Based on the attributes of a "typical" building in each size bin, energy use profiles were generated for each of 11 different cities with weather data. The result is a multidimensional table that describes the energy use of a building given its size and (weather) location. Therefore, for each hour, building size, and weather location, the building cooling can be expressed using the following variables: PeakCoolingByMonth, AnnualCoolingByHOD, PeakDayCoolingLoad, and AverageCoolingLoadProfile in the lookup table. These cooling profiles are used by the TES model, providing an integrated method to account for building energy profiles for various size buildings in various weather locations. 


\section{Appendix C: CBECS Data}

The Electronic Commercial Building Energy Consumption Survey (E-CBECS) was developed by Pacific Northwest National Laboratory (PNNL) for the US Department of Energy, Office of Buildings Technology (OBT). The data contained in E-CBECS are derived from the Commercial Buildings Energy Consumption Survey (October 1998), which is published by the Energy Information Administration (EIA).

CBECS is a national sample survey that collects statistical information on the consumption of and expenditures for energy in U.S. commercial buildings along with data on energy-related characteristics of the buildings. CBECS is conducted by the Energy Information Administration of the U.S. Department of Energy. The first CBECS was conducted in 1979 and then triennially since 1983. In the 1995 CBECS, there were 6,590 sampled buildings, of which 5,766 were successfully interviewed. Energy-related characteristics of the buildings are obtained in an on-site personal interview with the building managers, owners or tenants during the Commercial Buildings Characteristics Survey. Energy consumption and expenditures information are obtained from the energy suppliers to the responding buildings during the Energy Suppliers Survey. Commercial buildings are defined as enclosed roofed and walled structures used predominantly for commercial purposes with floor space greater than 1,000 square feet. This definition includes buildings such as schools, health care buildings, and religious institutions, as well as office buildings and retail stores.

The CBECS sample was designed so that survey responses could be used to estimate characteristics of the entire commercial buildings stock in the 50 states and the District of Columbia. This was accomplished by calculating basic sampling weights (base weights) to inflate sample data. Statistically, a base weight is the reciprocal of the probability of a building being selected into the sample. This is equivalent to saying that a base weight is the number of actual buildings represented by a sampled building. Thus, a sample building with a base weight of 1,000 represents itself and 999 similar, but unsampled, buildings in the total building stock.

\section{Office Buildings}

Querying the CBECS database gave a useful picture of the relative sizes of office buildings and the types of cooling equipment most frequently found. For this analysis, it was assumed that the distribution of sizes of office buildings in the Federal Sector is similar to office buildings in general. This assumption seems reasonable considering that the building sizes and types that set Federal buildings apart from the private sector tend to be related to aircraft servicing, military housing (barracks), and other non-office building types.

Figure $\mathrm{C} 1$ shows the distribution of the number of office buildings (counts) in each size bin. See Appendix B for information about the building size bins. Figure C2 is, as expected, the exponential relationship to the total floor area per bin. 


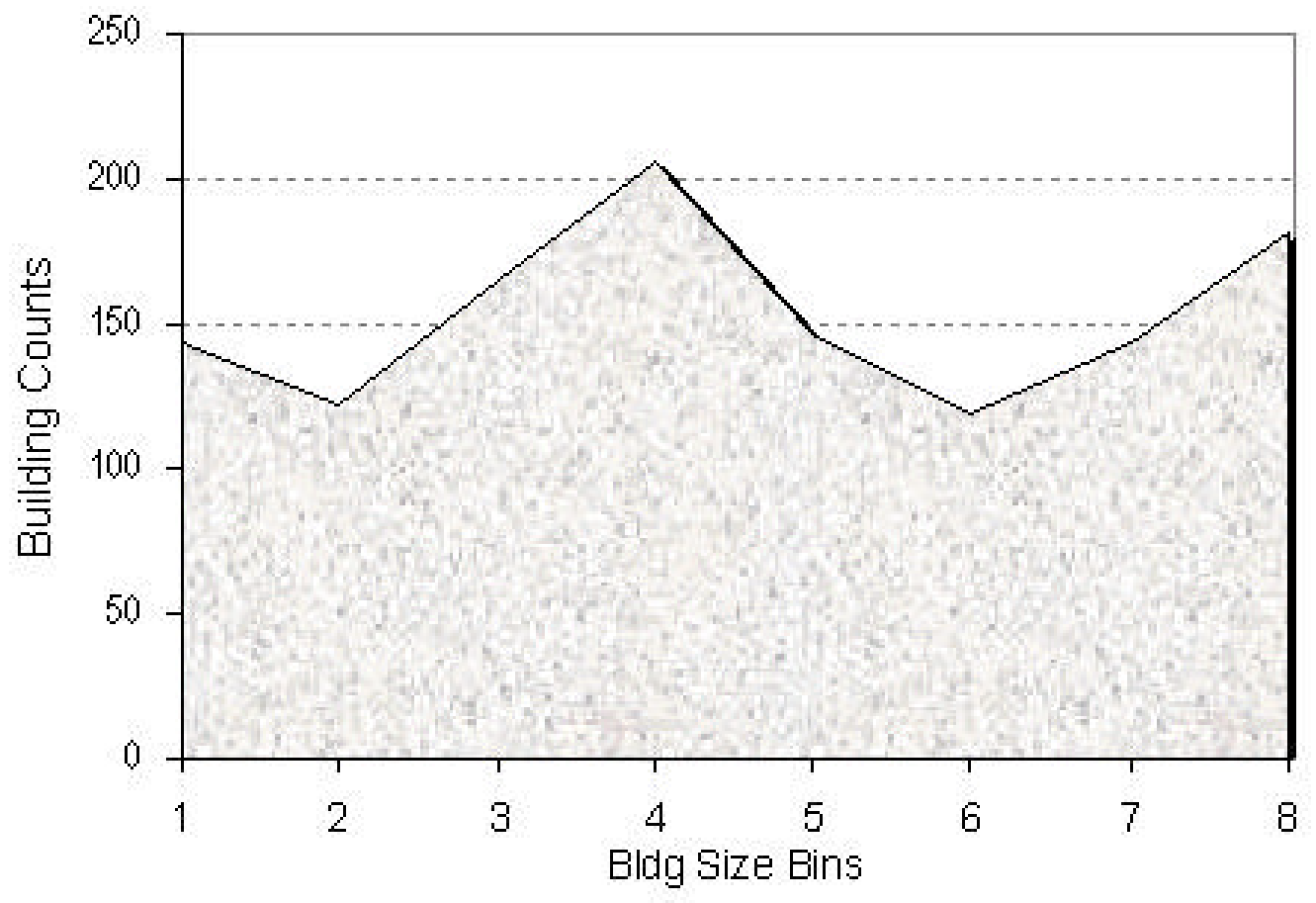

Figure C1. Building Size Distribution by Number of Buildings

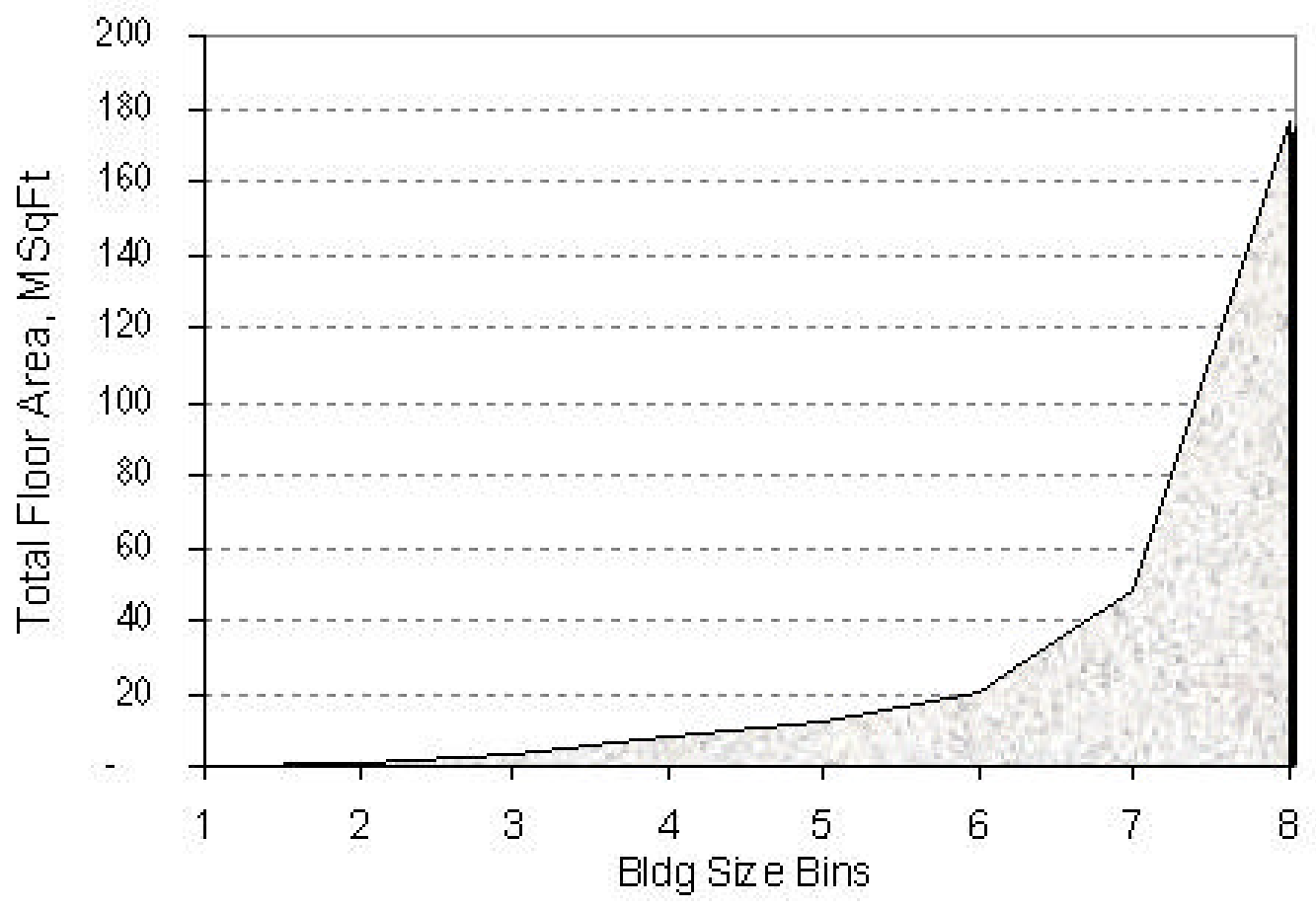

Figure C2. Building Floor Area by Size Bins 


\section{For more information}

Questions regarding the design or operation of E-CBECS may be posed to:

?? David Eike (PNNL (202) 646 7781, david.eike@pnl.gov )

Questions concerning the CBECS data may be referred to:

?? Jay Olsen ( EIA, (202) 586 1137, jay.olsen@eia.doe.gov )

For a detailed discussion of CBEC methodology, see the Commercial Buildings Section at http://www.eia.doe.gov/emeu/consumption/ 